\title{
Prescribing marijuana? You have more than 200 options
}

There are about 220 types of cannabis mentioned on the websites of Canada's 13 licensed medical marijuana growers. Several growers name their products after their companies. Others use names that resemble pharmaceutical names or allude to therapeutic benefits. Many growers, however, are using recreational names. They might want to reconsider that choice if they want the medical community to take them seriously, say health care branding experts. — Roger Collier, CMAJ

Link to full infographic: www.cmaj.ca /lookup/suppl/doi:10.1503/cmaj .144849/-/DC1

CMAJ 2014. DOI:10.1503/cmaj.109-4849

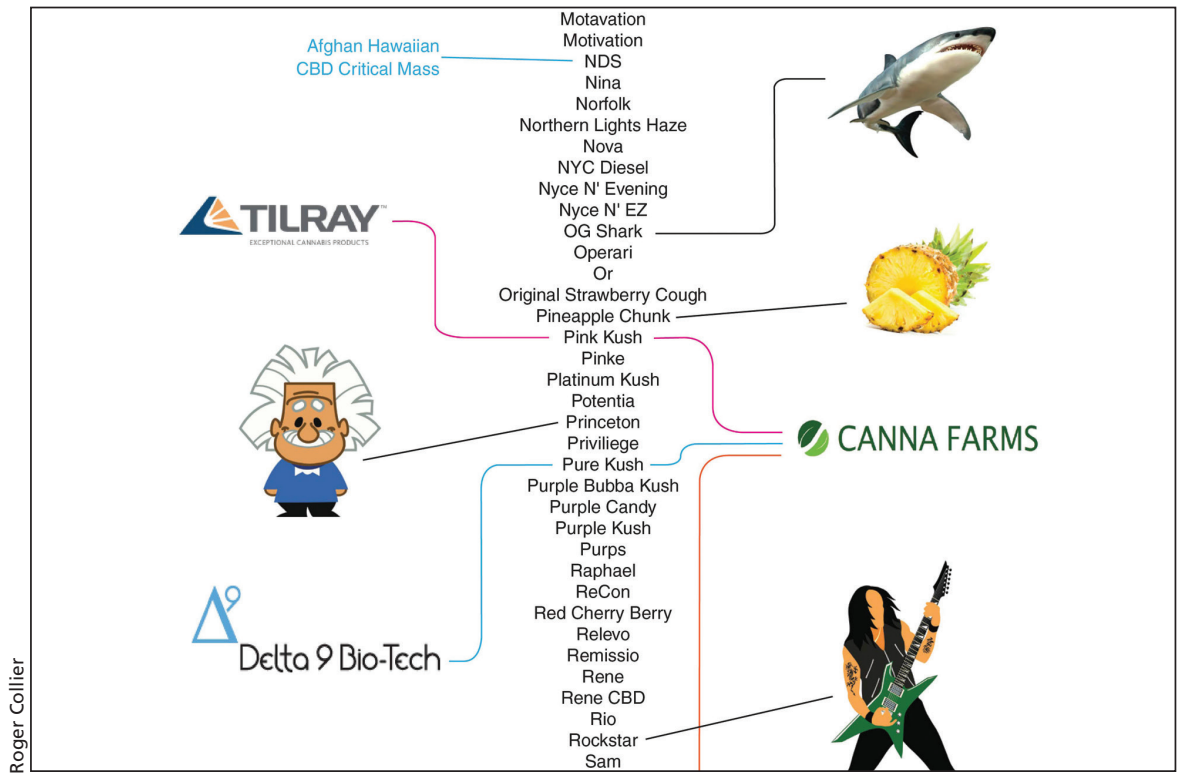

